\title{
Formação à informatica em Campinas: elementos e reflexões
}

\author{
Eliana Martins da Silva Rosado \\ Pontifícia Universidade Católica de Campinas
}

\begin{abstract}
Como formar à informática é problemática perseguida por pesquisadores e docentes na atualidade. O presente estudo teve por objetivos: a) avaliar o tipo de formação à informática oferecida por escolas especializadas em Campinas; b) explorar o espaço do vídeo dentro desta formação, articulado ao conceito de aprendizagem expresso nas representações sociais dos coordenadores desses cursos. Um questionário (questões abertas e fechadas) foi respondido individualmente por oito representantes de escolas. Principais resultados: quanto à estrutura das formações, dois grupos de escolas se destacaram; a) aquelas que ofereciam formações sobre informática de escritório ( $57 \%$ da amostra); b) estabelecimentos com formação menos orientada (uso de programas e programação, $43 \%$ da amostra), podendo haver populações-alvo (jovens ou adultos, $72 \%$ da amostra). O modelo implícito de aprendizagem subjacente não revelou um conjunto conceitual marcante dentro do qual o recurso ao vídeo poderia se claramente articulado, sendo distribuídas as dimensões entre ênfase na ação do aluno ( $37 \%$ do total de argumentos recolhidos), em seus pré-requisitos para a formação ( $32 \%$ dos argumentos) e métodos de ensino ( $32 \%$ dos argumentos). Conclusões: paradoxalmente, numa formação para a qual a prática com o computador é vista como fundamental, parece haver uma prédisposição desses docentes para o ingresso do vídeo na formação à informática. Todavia, a estrutura dos cursos sugeriria uma ausência de política de formação a essa tecnologia na região, necessitando de novas pesquisas para aprofundamento dessas tendências identificadas.
\end{abstract}

Palavras-chave: Formação à informática; representação social; video; modelo de aprendizagem.

\begin{abstract}
Computer science in Campinas: elements and considerations

To form for computer science is a problem porsued by researchers and teachers on the present time. The present study had for objectives: to evaluate the type of formation for computer science offered by specialized schools in Campinas, to explore the space of the video inside of this formation, articulated to the expressed learning concept in the coordinators' of those courses social representations. A questionnaire of open and shut questions was answered individually by eight representatives of the schools. Main results: with relationship to the structures of formations, two groups of schools stood out: those that offered formations on computer science for business (57\%), establishments with less formations (use of programs and programmigs - 43\%) could have targetpopulation (youth or adults, $72 \%$ ), The implicit model of underlying learning didn't reveal a defined conceptual group inside of which the resource to the video could be clearly articulated, being distributed the dimensions among enphasizing in the action of the student ( $37 \%$ of the picked up arguments), in its pré-requirements for the formation $(32 \%)$ and teaching methodd $(32 \%)$. Conclusions: in a formation for which the practice with computer is seen as fundamental, seems ther to be a pre disposition of those educational ones for the entrance of the video in the computer science formation. Though, the structure of the courses would suggest na absence of formation politics to that technology in tha area, being needed new researches for the better identification of those tendencies.
\end{abstract}

Key-words: formation for computers; social representation; video; learning' model.

Endereço para correspondência: Ponifícia Universidade Catolica de Campinas - Puc-Campinas Pós-Graduação em Psicologia, Rua Waldemar César da Silveira, 105, Swift, CEP 13045-270, Campinas, SP, E-mail: erosado@lexxa.com.br 


\section{O computador e as imagens:}

\section{uma nova, rica e complexa articulação}

A questão das contribuições das tecnologias na educação está longe de ter respostas conclusivas e, cada vez mais, atrai pesquisadores de áreas diversas. É uma constatação, por exemplo, que o advento da informática na educação trouxe, entre outros aspectos, o retorno de vários outros suportes de informações, agora articulados em programas de computador. Fala-se aqui das representações figurativas (imagens), sejam elas fixas, animadas, associadas ao som (músicas, ruídos etc) e que passam a integrar produtos como os CDRom's, que começam a tornar-se comuns mesmo em nosso país. A questão passa a ser apropriar-se disso, via educação, formação, com todas as controvérsias, conflitos e necessidades que tal situação passa a despertar, seja nas relações de trabalho em empresas, no ensino fundamental e técnico (professores e alunos em sua relação com o computador e o conhecimento nele veiculado), bem como na prática individual de diferentes profissionais (Bèlisle, Rosado, 1990).

Na formação ao uso de microcomputadores, o emprego de imagens diversas no aprendizado parece ser um avanço cada vez mais buscado por tais organizações de ensino. Sabe-se, assistematicamente, da procura de "data-show" como suporte de informações em formações à informática, sob a justificativa de que, substituindo o uso do retroprojetor, ter-se-ia a vantagem de permitir ao aluno o "acompanhamento" das diferentes ações do professor ao longo de demonstração de um determinado produto. Nessa perspectiva, seja o uso de CDRom, seja o recurso ao data-show, entende-se que existe a tentativa de buscar nas representações figurativas, um auxílio, um complemento, eventualmente mais uma fonte de informações para o processo ensino-aprendizagem. Em cada um desses casos, acredita-se que o tipo de relação do professor com a representação figurativa seja dife- renciado, quer no tocante aos objetivos buscados pelo docente quando seleciona o suporte que parece mais the convir, quer no tipo de relação que o aluno estabelece com a representação figurativa dentro do processo de aprendizado. Entende-se que a linguagem audiovisual pode potencialmente ser vista como um modo específico de aquisição de conhecimentos, estes também específicos (Rosado, 1992).

Diante desse quadro, uma questão importante parece se colocar: o referencial teórico disponível para o trabalho com imagem no processo ensino-aprendizagem (principalmente a imagem animada), baseia-se muito mais em pesquisas voltadas para a imagem fixa, numa abordagem fundamentada na Teoria da Informação. Entre outros aspectos, este modelo sugere que o aprendizado só pode ocorrer se, ao lado da mensagem, for possível retirar-se o máximo de ambigüidade dela, de maneira que o receptor neste caso, o aluno - seja capaz de decodificar com clareza a informação/conhecimento que se deseja transmitir. Assim, em muitas situações, as representações figurativas acabam transformando-se em gráficos ou esquemas, que esvaziados ao máximo de informações "não fundamentais" (ruídos), distanciam-se da representação da realidade, para traduzir relações julgadas imprescindíveis e presentes nela. Um esquema de funcionamento de uma máquina não traz em si todos os elementos que a compõem em funcionamento. Além disso, seu aspecto, em termos de representação, pode nem sempre lembrar uma máquina. Embora essas orientações não sejam aqui negadas em sua íntegra, o que se quer colocar é o fato de que, a imagem fixa ou animada (fotografia, seqüência de vídeo etc), acaba sendo preterida numa relação de aprendizagem, caso a abordagem da Teoria da Informação for levada ao seu extremo. Isso porque acredita-se que, apesar de contribuir para aumentar a motivação no ensino, auxiliar na 
compreensão de conhecimentos abstratos, facilitar a memorização (aspectos que não evidenciam o processo de interpretação do sujeito-aprendiz da mensagem com a qual interage), a imagem teria em si o risco de levar o aluno a "distrair-se", a distanciar-se do conteúdo principal a ser transmitido, trazendo prejuízo ou atraso no aprendizado. O potencial pedagógico que a mensagem audiovisual pode oferecer em contexto de aprendizagem, se inserida numa perspectiva de reconstrução do seu sentido por parte do aluno-telespectador, propiciando assim uma atividade psicológica intensa de tratamento dessa informação simbólica através de análises tanto do conteúdo como da forma da mensagem, fica excluído (Rosado, 1994a, 1994b)

Nesse confronto de posições teóricas diferentes, paradoxalmente o que parece acontecer é a necessidade que professores de novas tecnologias ressentem de uma ampliação do ângulo de visão a ser mostrado ao aluno e, para tanto, fazer em recurso às representações figurativas, usando inclusive aquelas para as quais os modelos teóricos disponíveis não são capazes de caracterizar com clareza as contribuições, o status da mensagem audiovisual na aprendizagem.

Paralelo a esse estado de coisas, existe certo número de produtos vídeo - convencionais, poder-se-ia dizer - que disponíveis em videolocadoras, buscariam auxiliar na formação ao uso às novas tecnologias. Todavia, uma análise mesmo superficial desses produtos acaba mostrando que se trata de material bastante antigo e provavelmente, pouco utilizado por consumidores, sejam eles profissionais em auto-capacitaçâo ou escolas de formação à informática. Evidentemente, um elemento restritivo quanto ao uso desses produtos está, efetivamente, na "idade" dos mesmos: a aparição num vídeo de um micro- computador cujas formas revelem máquinas muito antigas ou obsoletas acaba, infalivelmente, fornecendo uma atmosfera de ultrapassado, mesmo que o conteúdo a ser transmitido seja atual. Além disso, existe de fato uma rápida evolução tanto de hardware quanto de software, que torna a elaboração e comercialização de vídeos um campo de investimento complicado em termos financeiros e de atualização.

No entanto, parece que a proposta de articulação de um produto que conte com linguagem audiovisual com o discurso de um monitor é ainda atraente aos olhos daqueles que formam às novas tecnologias. Nessa perspectiva, o datashow parece favorecer, em parte, esse objetivo. Em um dos contatos estabelecidos no início dos trabalhos desta pesquisa, um diretor de escola de informática pareceu bastante interessado na perspectiva de se desenvolver uma forma de representação animada (vídeo?) que pudesse complementar o processo de formação. O que interessa ressaltar nesse momento é a busca, por parte desses profissionais, de melhor arranjo entre as possibilidades existentes, embora sem muita fundamentação teórica subjacente no que tange às contribuições efetivas desses arranjos para a aprendizagem.

Essa discussão fica ainda mais complexa se for levado em conta o discurso usual desses profissionais (e mesmo dos aprendizes) de que a única maneira de se aprender a trabalhar com informática é... praticando. Em nossa tese de doutoramento (Rosado, 1990), trabalhando com jovens adultos em formação à informática, pudemos constatar que não só esse discurso é uma constante, como a observação da prática desse aprendizado, numa perspectiva teórica baseada em Psicologia Cognitiva, revelou que $a$ noção de aprendizado é algo a ser muito aprofundado nesse campo. Aprender informática é saber fazer a máquina funcionar? É conseguir usar um programa qualquer, de 
maneira a atingir um objetivo proposto, como por exemplo, fazer um texto, elaborar e alimentar um banco de dados? Mas, e quando algo "não acontece como previsto", ou seja, não se obtém os resultados buscados dentro das condições de tempo e qualidade previstas, pode-se dizer que alguém aprendeu efetivamente a lidar com o programa, na medida que o aprendiz "não sabe como resolver o problema que se lhe apresenta"? Nessa perspectiva, como formar à informática, mesmo que se fale da informática de escritório (usuário e não programador ou analista de sistemas)?

$\mathrm{O}$ que pudemos observar em muitos momentos, foi um "tatear", por parte do alunoaprendiz, um "experimentar" seqüências de ações (acerto-erro?) até que o resultado esperado se apresente. Então, aprender a usar um programa é descobrir um conjunto de seqüências de ações, um "modus operandi" de um produto, sem que necessariamente se tenha uma visão completa da estrutura interna, das relações subjacentes a esse programa, das novas possibilidades de uso além das apresentadas "em curso"? Segundo Hoc (1987), essa postura revelaria a busca, por parte do aluno-usuário, de um conjunto de conhecimentos de natureza funcional, em detrimento de conhecimentos processuais. Os primeiros indicarão sequiências de ações a serem efetuadas, que levarão à obtenção de um objetivo, porém sem que o ator envolvido compreenda as razões de cada ação e mesmo de sua seqüência. Já os conhecimentos processuais articularão à essa seqüência de ações, elementos que definem e explicam cada fase empregada, bem como as ligações das fases além de conhecimentos referentes a mecanismos de controle de cada unidade da ação, permitindo assim a condição do sujeito intervir ativamente na resolução de um problema não previsto.

Essas colocações são aqui feitas para ressaltar-se a seguinte relação, que nos parece presente dentro de um modelo implícito de aprendizado que permeia o trabalho de professores e de alunos nesse campo: busca-se criar melhores condições para o aprendizado às novas tecnologias, e nessa perspectiva, a imagem animada parece ainda guardar em si ricas possibilidades.

Vale dizer que dentro dessa relação, não só a dimensão cognitiva, intelectual dos atores envolvidos entra em jogo, mas também um componente psicossocial: a percepção, o significado que alunos e professores usam para lidar com a situação de aprendizagem (que modelo de aprendizagem implícito em cada sujeito rege suas condutas na formação?) bem como dos recursos utilizados para tal fim (qual o "lugar" da linguagem audiovisual dentro de uma formação à informática para esses atores?), constituem variável interveniente importante no processo. Nessa medida, o conceito de representação social (Moscovici, 1978; Jodelet, 1995), vista como construção elaborada pelos atores envolvidos dentro de situações similares e que definem quadros de referência para os sujeitos que interpretam o que lhes acontece e modulam suas condutas em conseqüência, tem-se mostrado ferramenta teórica bastante rica em trabalhos semelhantes que pudemos fazer. Assim, se para alunos e professores as concepções de aprendizado de informática repousam sobre a idéia de que só a prática é que pode levar ao domínio da máquina, entendemos estar diante de um eixo para o qual a sistematização de Moscovici pode ser de grande valia na compreensão dos fenômenos alí subjacentes.

E foi justamente aqui que buscamos explorar o conceito de aprendizagem, visto que alguém que terminou uma formação, nem sempre encontra-se efetivamente capacitado a usar os conhecimentos adquiridos na prática, sejam quais forem as circunstâncias que the forem apresentadas. $\mathrm{O}$ uso efetivo, parece restringir-se aos "casos tratados em aula", o que com 
freqüência, não correspondem à realidade de trabalho de cada profissional envolvido com um microcomputador em seu exercício profissional (Bèlisle, Rosado, 1990).

Essa contradição, e o já apontado limitado campo teórico que fundamente o uso articulado da imagem animada a outros recursos na formação (não so à informática, mas na educação em geral), parecem elementos suficientes para que pesquisadores se debrucem sobre tais relações. Saliente-se que, na França por exemplo, no final dos anos 80, vários pesquisadores se questionavam sobre qual a melhor maneira de formar às novas tecnologias, tal como exemplifica o livro Quelle pédagogie pour les nouvelles technologies?, (Malglaive, org. 1987). No Brasil, pouco pôde-se encontrar em termos de pesquisas que visassem aprofundar esse tipo de relações.

Foi nessa perspectiva que se buscou, num primeiro momento como objetivo geral, explorar o espaço de formação à informática na região de Campinas, através de questionamentos feitos junto a coordenadores pedagógicos e/ou monitores desse campo, visando-se conhecer como vem sendo feita a formação à informática: que meios são privilegiados, que métodos são preferidos, que características tem a população que busca essa formação, que modelos implícitos de aprendizagem estão efetivamente presentes nessa realidade educacional, qual o espaço ocupado pela linguagem audiovisual na formação à informática.

\section{Método}

\section{Caracterização da amostra}

Uma primeira dificuldade a ser salientada nesse momento refere-se à delimitação da população a ser questionada. Em nossa experiência fora do Brasil, pudemos efetuar o mesmo trabalho numa cidade francesa (Lyon), e foi possível servir-se dos meios de comunicação habituais do país: listagem telefônica apresentada via minitel - visor oferecido pela companhia telefônica que, acoplado ao telefone, permitia o acesso temático a diferentes serviços, incluindo-se o anuário telefônico. Através desse suporte, identificou-se uma centena de escolas de informática em funcionamento na cidade (cujas dimensões em termos populacionais eram bastante equivalentes à cidade de Campinas), obtendo-se assim as coordenadas necessárias para envio de correspondência.

No Brasil, como ainda não existe esse tipo de serviço, buscou-se seu equivalente, a lista telefônica. Constatou-se a curto prazo a ineficiência dessa fonte de informações. Compôs-se então, através das fontes, meios de comunicação social (out-doors, anúncios de rádio, etc), lista telefônica e informações de profissionais da área, uma população de escolas que fornecessem formação à informática na cidade. Obteve-se um total de vinte estabelecimentos, para os quais foi enviado nosso instrumento de coleta de dados.

Nessa perspectiva, vale salientar uma primeira constatação: aquele que busca uma formação à informática, acaba sendo obrigado a utilizar os meios de comunicação social como forma de acesso a seu objetivo, com todos os limites e as características que essa fonte pode traduzir (época em que o sujeito busca o curso em relação à presença de publicidade sobre esta ou aquela escola, colegas e/ou conhecidos que tenham feito curso em determinada escola, por exemplo).

Das vinte escolas contatadas, dez retornaram o questionário respondido, sendo que somente oito puderam ser efetivamente utilizados, visto que dois estabelecimentos não eram, na verdade, organismos de formação à informática. Isso eqüivale dizer que, se foi possível 
chegar-se à quase totalidade de escolas de informática da região, o presente levantamento foi baseado em $40 \%$ do total de estabelecimentos da cidade.

Embora percentualmente este seja um índice bastante bom, principalmente referente a uma pesquisa feita via correio, dois pontos precisariam ser ressaltados:

1. Tal como será melhor descrito no procedimento de coleta de dados, o envio pelo correio foi acompanhado de envelope selado, o que facilitaria o retorno dos dados. Além disso, solicitava-se ao respondente que, caso não quisesse responder, ou se não se considerasse um sujeito da amostra, que devolvesse o questionário em branco, como uma forma de analisar-se a qualidade das informações que auxiliaram a compor a amostra. Somente dois casos que não se aplicavam foram devolvidos, e um total de dez escolas não se manifestaram quanto à nossa solicitação de retorno, mesmo em branco. Desinteresse pelo trabalho de pesquisa? Preocupação mercadológica em não desvendar formas de trabalho de algumas escolas? Não foi possível identificar com precisão as razões desse tipo de conduta das escolas em questão;

2. se vinte escolas é o total de estabelecimentos de ensino que formam à informática numa cidade com por volta de 900 mil habitantes, tida como um dos pólos de desenvolvimento do país, será que esse não é um número reduzido para responder à demanda da sociedade? Ou tal demanda não se acha efetivamente voltada para esse tipo de formação na região? Eis aqui outro conjunto de interrogações que precisaria ser melhor aprofundado em trabalhos ulteriores.

Do total de indivíduos que responderam ao questionário, $43 \%$ eram coordenadores pedagógicos das escolas em questão e os demais
$57 \%$ dos sujeitos eram professores ou instrutores dessas escolas.

\section{Instrumento de coleta de dados: questionário}

Optou-se por um questionário composto de 23 questões abertas e fechadas para explorar-se os objetivos do trabalho, a saber, caracterizar-se o tipo de formação à informática oferecido pelas escolas da cidade evidenciando-se o espaço concedido ao vídeo nessa capacitação.

As variáveis efetivamente exploradas no levantamento encontram-se discriminadas abaixo:

Tabela 1. Variáveis exploradas

\begin{tabular}{|l|l|}
\hline Variáveis & $\mathbf{n}^{\circ}$ das questões \\
\hline 1. caracterização da formação & $1 ; 2 ; 3 ; 4 ; 7 ; 8 ; 9 ; 10 ; 11 ; 12 ; 13 ; 14$ \\
\hline 2. caracterização da clientela & $5 ; 6$ \\
\hline $\begin{array}{l}\text { 3. posicionamento: vídeo na } \\
\text { formação }\end{array}$ & $15 ; 16 ; 17 ; 18 ; 19 ; 20$ \\
\hline $\begin{array}{l}\text { 4. modelo implícito de apren- } \\
\text { dizagem }\end{array}$ & $21 ; 22$ \\
\hline 5. críticas/sugestões & 23. \\
\hline
\end{tabular}

\section{Procedimento de coleta de dados}

Uma vez identificadas as escolas com as quais se trabalharia, uma carta impressa em papel timbrado da universidade à qual a pesquisadora se achava vinculada, explicando os objetivos do trabalho e solicitando o envio em qualquer circunstância do instrumento foi elaborada. Em envelope foram inseridos cópia do questionário acompanhada da carta explicativa e um segundo envelope selado, destinado ao retorno do questionário. Esse conjunto de dados foi colocado no correio, tendo-se quinze dias de intervalo solicitado entre o envio da correspondência e a data máxima de retorno das informações. 


\section{Resultados e discussão}

\section{Caracterização da formação à informática oferecida na cidade de Campinas}

No que se refere à variedade de cursos cobertos pelas escolas, notou-se que a grande maioria oferecia dois grandes eixos de formação:

a) introdução à informática, incluindo-se nesse eixo a capacitaçâo de programas específicos. Todas as escolas em questão ofereciam a iniciação à informática. Seis das sete escolas $(86 \%$ do total da amostra), ofereciam capacitaçâo a programas específicos.

b) programação, indo desde a formação básica até a avançada. Três escolas faziam esse tipo de formação (tanto a básica como a avançada), num total de $43 \%$ da amostra investigada.

$\mathrm{Na}$ verdade, pôde-se constatar que a amostra foi composta por dois tipos de estabelecimento de ensino:

1. Um primeiro, cujo tipo de formação focalizaria muito mais as necessidades empresariais da região, em termos de serviços terciários. Ou seja, a introdução à informática e a capacitaçâo em determinados tipos de programas eram as atividades básicas de $57 \%$ do total de escolas investigadas. Os programas cobertos eram principalmente processamento de textos e planilhas (Word 6.2; MS-Works; Aldus; Word Perfect; Excel; 4-PRO). Todas as escolas deste subgrupo ofereciam essas formações. Cursos sobre gráficos, banco de dados e editoração eletrônica eram ministrados em somente duas das quatro escolas deste subgrupo. Somente uma escola fazia formação em administração de arquivos.

Nota-se que o marcante nesse tipo de estabelecimento é a capacitaçâo em processamento de texto e planilhas, embora a variedade de programas utilizados não pareça corresponder a uma gama importante, principalmente se notarmos que cada escola apresentou seu próprio conjunto de programas trabalhados. Chega-se a suspeitar de uma "divisão de mercado" através de programas cobertos, pois excetuando-se pelo Excel, que aparece em duas das quatro escolas deste subgrupo, nenhum outro nome de programa surgiu em mais de uma escola. Uma outra hipótese também poderia ser o acesso diferenciado aos diferentes produtos existentes, por exemplo, determinados tipos de programas (inclusive em termos de capacitação dos professores do estabelecimento de ensino para lecionar novos programas) que determinariam a "parte de mercado" de cada escola ou grupo delas. Todavia, o número de escolas desta amostra parece muito pequeno para que se tire conclusões a esse respeito.

2. Um segundo grupo de escolas (43\% do total da amostra), cujos questionários foram respondidos sempre pelos coordenadores pedagógicos, parece mais abrangente, fornecendo uma formação não só voltada para a capacitaçâo de profissionais de outras áreas que necessitariam trabalhar com ferramentas informáticas, mas oferecem igualmente formações em programação e análise de sistemas (neste caso, somente uma dessas três escolas). Note-se que são escolas cujo contingente em termos de alunos não excede 140 indivíduos, com a maioria em torno de 90 freqüentadores. Incluiu-se também neste subgrupo, escolas cujo objetivo é formar técnicos em outras áreas (eletrônica, telecomunicações, alimentos, automação em processos industriais, etc), sendo que a informática entra como um dos elementos dessa profissionalização.

Nestas, para a capacitaçâo em programas, é de se ressaltar a formação em Word e Wordstar, sem especificação da versão. Quanto às planilhas, aparecem Lotus e 4PRO (este, somente para uma das escolas). Para os bancos de dados é ministrado o uso de DBase3 e Clipper. 
Quanto aos tipos de formação oferecidos, os mais freqüientes eram os cursos teórico / práticos de 30 e 180 horas, ministrados por três escolas, incluindo-se aqui uma das correspondentes ao primeiro grupo caracterizado acima. No geral, as formações podiam variar de um a dois dias, até 180 horas, para as escolas especializadas em formação à informática.

Do total de escolas investigadas, duas delas $(28 \%$ da amostra) ofereciam essencialmente formação de curta duração (máximo de 24 horas), sendo estas organizações que faziam exclusivamente formações de iniciação e capacitaçâo de programas. Duas outras escolas (28\% da amostra), faziam formação técnica profissionalizante, gerando portanto diplomas de natureza diversa dos anteriores. Tratava-se assim, de cursos mais longos, com 360 horas no mínimo. Já o ultimo subgrupo da amostra (43\% das escolas) ofereciam prioritariamente formações de 180 ou 360 horas, existindo entre elas uma escola que oferece exclusivamente cursos de iniciação/capacitaçâo, enquanto as demais tinham um âmbito de atuação mais amplo.

Quanto à estrutura das formações oferecidas têm-se que nenhuma das escolas investigadas oferecia formações individualizadas ou em grupos até oito alunos. Em sua grande maioria, as classes eram formadas com número variando de 9 a 20 alunos (62,5\% das indicações), e três escolas ofereciam ainda formação para classes de mais de 20 alunos (37,5\% das respostas).

Normalmente, o local de formação era a própria escola, com $87,5 \%$ das indicações. Somente uma escola oferecia também cursos em empresas ou entidades solicitantes (12,5\% das indicações). Ainda em termos da estrutura de curso, no que tange à distribuição número de alunos por microcomputador, a condição de um terminal para cada dois alunos era a privilegiada, com $55,6 \%$ das indicações.
As referidas escolas da amostra, em sua maioria, entendiam que desenvolviam outras atividades além da formação $(85,71 \%$ das escolas): diplomas de natureza diversa da informática (formação em eletrônica, telecomunicações, alimentos, instrumentação para controle de processos industriais, tal como já indicado), ou serviços prestados a empresas (seminários e cursos, desenvolvimento de aulas multimídia para utilização interna, etc).

Quanto às estratégias pedagógicas mais utilizadas:

a) o total de respostas recolhidas revelou que as escolas no geral, utilizavam-se de uma média de três estratégias de ensino (média exata $=3,43$ estratégias);

b) a mais comum, para $100 \%$ das escolas investigadas eram os exercícios práticos. Seguem-se a estes as aulas expositivas, com $29 \%$ do total de indicações, sendo utilizada por seis das sete escolas investigadas;

c) duas outras alternativas também foram apontadas: atividades complexas simuladas através de programas de computador (exercícios de resolução de problemas?) com $21 \%$ das indicações, e acompanhamento de atividades reais dos estudantes, trazidos como exemplo à sala de aula $(21 \%$ das indicações).

Quanto aos recursos e suportes, o mais usado foi, evidentemente, o microcomputador: $100 \%$ das escolas serviam-se dessa ferramenta. Além disso, os livros, os manuais de softwares e o retroprojetor foram indicados por seis escolas ( $86 \%$ do total da amostra).

A salientar-se a indicação de uso de vídeo, para $57 \%$ dos estabelecimentos investigados, o que parece-nos bastante interessante. Note-se que esse suporte parecè ser mais usado do que outros mais em acordo com a tecnologia 
em questão, ou seja o data-show, que somente duas escolas usavam ( $29 \%$ da amostra) e os tutoriais (uma escola, correspondendo a 14\% da amostra). As revistas específicas eram utilizadas na mesma porcentagem que os vídeos, ou seja, o faziam $29 \%$ da amostra.

\section{Caracterização da clientela recebida nos cursos de informática}

Do total de escolas investigadas pode-se constatar que, em termos de faixa etária, os jovens de até 18 anos eram o contingente mais presente, aparecendo em $71 \%$ das escolas. Os adultos apareciam em $57 \%$ dos estabelecimentos.

Em função da clientela visada, pôde-se identificar três tipos de organização:

a) aquelas que se mostrariam prioritariamente voltadas para a formação de jovens, compondo $43 \%$ da amostra. Nesses estabelecimentos os respondentes não fizeram discriminação quanto a uma predominância maior ou menor de homens ou mulheres seguindo as formações;

b) aquelas que pareceriam mais voltadas para a formação de adultos, compondo $29 \%$ da amostra. Nesses estabelecimentos, não pareceu haver predominância de homens ou mulheres no curso;

c) escolas que pareciam não ter uma população alvo (28\% da amostra). Nestas, a indicação de predominância de homens parecia existir, segundo as respostas dos professores. Note-se que estas eram escolas que forneciam essencialmente iniciação à informática e capacitaçâo a programas específicos.

Uma análise segundo a distribuição por tipo de clientela recebida pelas escolas revelou o seguinte: a) em escolas que visavam principalmente os jovens, as principais razões que pareciam trazê-los aos cursos, na opinião dos professores, reportavam-se à busca de uma profissão.;

b) das escolas que voltavam-se principalmente para adultos, numa delas a freqüência maior parecia ser de profissionais desempregados que buscavam melhorar seus currículos, enquanto que o outro estabelecimento em questão, indicava principalmente a solicitação de capacitaçâo via empregadores;

c) quanto às escolas que abrangiam uma clientela mais heterogênea, parecia que todas as razões já indicadas anteriormente apareceram nas respostas.

\section{Posicionamento quanto ao uso do vídeo na educação}

Duas orientações principais foram dadas a essa variável: a exploração do posicionamento dos professores quanto ao uso do vídeo na educação em geral e na formação à informática em particular.

As contribuições do vídeo na aprendizagem em geral pareceram constituir-se numa noção bastante aceita junto aos professores investigados. Obteve-se um total de $86 \%$ das respostas que indicavam a aceitação dessa afirmação. Assim, seis dos sete instrutores e coordenadores investigados apontaram para essa idéia. Um deles somente ( $14 \%$ da amostra), afirmava que tal postulado dependia da situação.

As argumentações que sustentavam tal posicionamento foram exploradas via questão aberta, cujos dados foram tratados através de análise de conteúdo (Bardin, 1996) e apresentados na tabela 2, a seguir. 
Tabela 2. Argumentos que fundamentam o posicionamento dos professores quanto ao uso de vídeo na educação.

\begin{tabular}{|l|c|c|c|c|c|}
\hline Categoria inicial & F & \% & Categoria global & F & $\%$ \\
\hline interativo & 1 & 7 & & & \\
vivência & 1 & 7 & Efeitos no aluno & 5 & 36 \\
memorização & & 2 & $\mathbf{1 4}$ & & \\
rapidez & 1 & 7 & & & \\
uso adequado & & & & & \\
atualização & 2 & 14 & & \\
\hline discussão & 1 & 7 & Metodologia de & 8 & 57 \\
ele/opraticos & 1 & 7 & uso & & \\
auxiliar & 3 & 21 & & & \\
\hline TV veículo habitual & 1 & 7 & Geral & 1 & 7 \\
\hline Total argumentos & $\mathbf{1 4}$ & $\mathbf{1 0 0}$ & & $\mathbf{1 4}$ & $\mathbf{1 0 0}$ \\
\hline
\end{tabular}

Encontrou-se três categorias globais de respostas oferecidas pelos professores: ênfase nos efeitos no aluno (36\% dos argumentos recolhidos), ênfase na metodologia de uso do vídeo ( $57 \%$ dos argumentos recolhidos) e ênfase em idéias mais gerais acerca da linguagem audiovisual como meio de comunicação (7\% do total de argumentos). Estas primeiras constatações indicaram que para o docente em informática, a questão do tipo de uso que se faz do vídeo em sala de aula é o fator mais importante quando se pensa nas contribuições da linguagem audiovisual na educação.

Dentro desta ótica, da metodologia de uso, existiu a clara noção de que o video deve ser um complemento no processo ensino-aprendizagem. Pode-se supor que o espaço oferecido ao suporte seria o de ilustrar conhecimentos já ministrados através de outros meios, como por exemplo a aula expositiva. Nessa perspectiva, a especificidade da linguagem audiovisual não chega a ser trabalhada como fonte de aprendizagem em si, levando o aluno à observar, analisar, criticar, comparar, levantar questões, sintetizar, concluir.

No que tange ao eixo de reflexão voltado para os efeitos no aluno (36\% dos argumentos recolhidos), os argumentos concentraram-se na questão da rápida memorização, fatores que não se referem ao processo de aprendizagem em si, mas ao resultado desta, identificado posteriormente em respostas verbais ou práticas dos alunos. Além da ênfase nos resultados da aprendizagem, existiu tentativa dos professores de evidenciar aspectos que referem-se à natureza da relação do aluno com o suporte. Todavia, elementos como "vivência a aprendizagem" e "o video é uma ferramenta interativa", evidenciam somente que o uso do vídeo pode provocar algo de diferente em termos de relação do aluno com o conhecimento a ser adquirido.

Já o terceiro eixo de reflexão, voltado para aspectos mais gerais da linguagem audiovisual na sociedade, mostra argumento que afirma a familiaridade e a preferência do aluno pela linguagem audiovisual, tomando como referência o consumo de televisão.

Concluiu-se, num primeiro momento que, existiria uma pré-disposiçâo dos docentes investigados em enxergar na linguagem audiovisual, contribuições para o processo ensinoaprendizagem. Tais contribuições seriam apoiadas em argumentos que definem um espaço do vídeo como auxiliar na aprendizagem, excluindo-se a especificidade do suporte como fonte de aquisição de conhecimentos. Ainda, tal contribuição foi apresentada sob a forma de argumentos que não identificavam as relações entre linguagem audiovisual e processo de aprendizagem em si, ficando os docentes muito mais na análise dos resultados mostrados pelo aluno, nos efeitos provocados pelo uso do suporte no ensino.

Já quando questionados sobre as contribuições do vídeo no aprendizado da informá- 
tica, as respostas assumiram outra orientação: somente para $43 \%$ da amostra, o vídeo seria um suporte produtivo na aprendizagem da informática. Já para 57\% dos sujeitos, o uso do vídeo na formação a essa disciplina foi visto com reservas: precisaria ser devidamente controlado para ser eficiente.

A análise do conteúdo de questões abertas feitas revelou alguns dados interessantes que acham-se discutidos abaixo.

Tabela 3. Argumentos que fundamentam o posicionamento dos docentes quanto ao uso do vídeo na formação à informática

\begin{tabular}{|c|c|c|c|c|c|}
\hline Categoria inicial & $\mathbf{F}$ & $\%$ & $\begin{array}{c}\text { Categoria } \\
\text { global }\end{array}$ & $\mathbf{F}$ & $\%$ \\
\hline consolida conteúdo & 1 & 8 & \multirow{7}{*}{$\begin{array}{c}\text { Efeitos no } \\
\text { aluno }\end{array}$} & \multirow{7}{*}{5} & \multirow{7}{*}{39} \\
\hline interativo & 1 & 8 & & & \\
\hline vivência & 1 & 8 & & & \\
\hline memorização & 1 & 8 & & & \\
\hline rapidez & 1 & 8 & & & \\
\hline interativo/micro & 1 & 8 & & & \\
\hline uso correto & 1 & 8 & & & \\
\hline & 2 & 15 & \multirow[t]{2}{*}{$\begin{array}{c}\text { Metodologia } \\
\text { de uso }\end{array}$} & \multirow[t]{2}{*}{5} & \multirow[t]{2}{*}{38} \\
\hline complemento & 1 & 8 & & & \\
\hline programação/não & 1 & 8 & \multirow[t]{2}{*}{ Tema } & \multirow[t]{2}{*}{2} & \multirow[t]{2}{*}{15} \\
\hline postura prof/sim & 1 & 8 & & & \\
\hline TV meio habitual & 1 & 8 & Geral & 1 & 8 \\
\hline Total argumentos & 13 & 100 & & 13 & 100 \\
\hline
\end{tabular}

Quatro eixos de reflexão principais foram usados pelos professores investigados para posicionar-se a esse respeito: os efeitos sobre o aluno, a metodologia de uso do vídeo na formação, aspectos relativos ao tema apresentado em vídeo e elementos de uma discussão mais geral, ligada aos meios de comunicação na sociedade. Esses temas receberam importância variada junto aos professores para explicar a pertinência do vídeo na formação à informática: os efeitos sobre o aluno e a metodologia de uso receberam em seu conjunto $77 \%$ dos argumentos recolhidos. Ou seja, a preocupação dos instrutores e coordenadores estava em como usar o recurso de modo a atingir determinados objetivos no aluno. As demais categorias, a saber, tema do vídeo e a televisão como meio de comunicação, receberam cada uma $8 \%$ do total dos argumentos recolhidos na questão.

A análise das categorias iniciais de respostas que compuseram o eixo de argumentos efeitos no aluno (39\% do total de argumentos recolhidos) indicou que, tal como sugere seu título, a observação dos professores acaba se apoiando novamente sobre aspectos que são decorrentes dessa interação. $\mathrm{O}$ aluno memoriza mais rapidamente, vivencia (psicologicamente?) o que aprende, ou ainda, o vídeo consegue consolidar conteúdos já ministrados pelos professores. Não ficou claro como o professor identifica essa última relação, podendo-se no entanto inferir que as respostas dos alunos, seja em nível verbal como na prática, forneceriam indicações dessa consolidação.

Todavia, é de se salientar que não houve qualquer indicação clara sobre o tipo de contribuição que o vídeo traria para o processo de aprendizado em si. Saliente-se que, do mesmo modo, notou-se, em outros momentos, que o professor trazia afirmações sobre a absoluta necessidade do aluno praticar para garantir o aprendizado. Essa noção também não foi aprofundada pelo professor, ou seja, como o praticar (repetir) levaria à aprendizagem, em termos cognitivos: não se fala em aspectos como "adquirir modelos", ou "gerar a extração de relações", etc.

O eixo de reflexão voltado para a metodologia de ensino (39\% do total de argumentos recolhidos) pareceu funcionar como comple- 
mento dos argumentos que focalizam os efeitos sobre o aluno. Assim, os professores investigados afirmaram apostar nas contribuições do vídeo na aprendizagem desde que, atualizado, corretamente usado (o que seria isso?), como auxiliar/ complemento de outros métodos pedagógicos ou (mais em acordo com a evolução da tecnologia), articulado a um micro.

Constatou-se assim, que as contribuições do vídeo na aprendizagem foram muito mais presentes no discurso destes professores referentes às condições de uso para assegurar aprendizado. Aparecem menos idéias relativas a ganhos que a linguagem audiovisual em si poderia oferecer ao conhecimento. Entende-se que a noção subjacente a esses argumentos indicaria que sem essas preocupações totalmente solucionadas, os objetivos educacionais não seriam atingidos. Certo receio do vídeo - da imagem estaria por traz disso? Visão pouco clara das contribuições da linguagem audiovisual na aquisição de conhecimentos? Acredita-se que ambas hipóteses têm sua presença na relação do docente em informática com o vídeo.

As condições apresentadas acima levam a outro conjunto de reflexões: uma aula expositiva, não necessitaria também de cuidados parecidos? A escolha de um manual para aprendizagem de um programa determinado, não deveria ser igualmente alvo dessa preocupação dos docentes? Sabe-se, assistematicamente, que muitas pessoas tentam aprender a usar micros com o auxilio de manuais, mas acabam logo abandonando esse recurso para explorar a máquina em si, via ensaio-e-erro.

Muitas vezes, os argumentos que sustentam essa atitude voltam-se para a linguagem complexa dos manuais, para a organização de informações que dificultaria a compreensão mais contextualizada do modo de utilização e de funcionamento do micro e/ou programa estudado. Todavia, a referência nesse sentido a suportes mais legitimados como o escrito e a aula, nem sempre recebem essas apreciações dos docentes. Poder-se-ia esperar, por exemplo, que os professores utilizassem o espaço para complementos, críticas e sugestões previsto no questionário para tais colocações. Contudo, isso não foi feito pelos sujeitos.

Quanto aos demais eixos de reflexão usados pelos professores nesta questão, tem-se a acrescentar algumas colocações. Quanto à ênfase no tema apresentado em vídeo (15\% dos argumentos recolhidos), os professores acabaram analisando, embora superficialmente, a adequação da linguagem audiovisual para determinados assuntos a serem tratados. Assim, programação não parece ser um tema a ser transmitido via linguagem audiovisual, enquanto que aspectos ligados à postura profissional, $\mathrm{sim}$.

O posicionamento dos professores poderia estar vinculado a experiências específicas com o suporte. Nesse sentido, buscou-se conhecer a familiaridade dos docentes com o vídeo na formação à informática. Como resultado, constatou-se que $71 \%$ da amostra afirmava ter conhecimento de produtos (vídeo) voltados para a formação à informática. Já $29 \%$ dos sujeitos indicavam não ter familiaridade com tais produtos, nunca tendo assistido vídeos específicos para formação à informática.

Daqueles que afirmavam ter conhecimento sobre vídeo, buscou-se explorar quais produtos tinham contatado e suas opiniões a respeito deles. Quanto aos produtos, cinco temas básicos apareceram: conceitos básicos sobre informática, aplicativos, DOS, hardware e processadores TGATO. 
As opiniões dos professores a respeito dos produtos foram organizadas em dois blocos: a ênfase nos aspectos positivos ( $40 \%$ dos argumentos) e a ênfase nos aspectos negativos (60\% dos argumentos).

Quanto aos aspectos positivos, os argumentos focalizaram duas direções principais: a construção do produto focalizada na qualidade das explicações e a relação do sujeito com o vídeo, expressa pela noção de que é de fácil compreensão, favorecendo a consolidação de experiências e prática. Apesar de pouco presente, tais reflexões pareceram mostrar que os professores que assim referiam-se aos produtos, tentaram fazer uma análise mais aprofundada, explorando os produtos em sua estrutura interna como na relação proposta ao aluno.

O mesmo não aconteceu com os argumentos referentes aos aspectos negativos. Nestes, o grande contingente de argumentos foi de natureza mais superficial e geral, tal como “simples", "supérfluo", "bastante fraco", etc. Tais argumentos revelam uma impressão global do professor, pouco elaborada a partir de uma análise mais aprofundada do suporte em si.

Concluiu-se, portanto, que embora a maioria dos professores investigados conheça alguns produtos vídeo voltados para a formação à informática, a variedade de produtos vistos não seria grande. A avaliação dos instrutores e coordenadores sobre a qualidade desses produtos acabou caindo muito mais nos aspectos negativos do que nos positivos. A natureza desses argumentos revelou que quando o professor avalia positivamente, parece ter mais condições de fundamentar sua posição partindo da análise do produto. Já quando o professor aponta os aspectos negativos, as argumentações são mais gerais, pouco voltadas para a análise dos produtos em si.
Tabela 4. Argumentos positivos e negativos referentes ao posicionamento de professores quanto a produtos vídeo sobre informática

\begin{tabular}{|l|r|r|l|l|l|}
\hline Categoria inicial & F & \% & $\begin{array}{c}\text { Categoria } \\
\text { global }\end{array}$ & F & $\%$ \\
\hline explicações detalhadas & 1 & 7 & & & \\
sequeência elaborada & 1 & 7 & & & \\
fácil compreensão & 1 & 7 & $\begin{array}{c}\text { Aspectos } \\
\text { positivos }\end{array}$ & 6 & 40 \\
consolida conceitos & 2 & 13 & & \\
consolida experiência & 1 & 7 & & & \\
simples & 1 & 7 & & & \\
supérfluo & 1 & 7 & & & \\
bastante fracos & 1 & 7 & & & \\
monótono & 1 & 7 & & & \\
\hline técnico & 1 & 7 & $\begin{array}{l}\text { Aspectos } \\
\text { negativos }\end{array}$ & 9 & 60 \\
muito conceitual & 1 & 7 & & & \\
não interativo & 1 & 7 & & & \\
manual substituiria & 1 & 7 & & & \\
como fazer sem o PQ & 1 & 7 & & & \\
\hline Total argumentos & $\mathbf{1 5}$ & $\mathbf{1 0 0}$ & & \\
\hline
\end{tabular}

\section{Modelo implícito de aprendizagem}

Quanto à visão dos docentes investigados referentes à aprendizagem em geral, obteve-se um conjunto de três categorias principais de respostas: a ênfase na ação do aluno (50\% dos argumentos coletados), a ênfase nos pré-requisitos do aluno (33\% dos argumentos coletados), e a ênfase no ensino (16\% dos argumentos apresentados). Observou-se rapidamente que, para esse conjunto de professores, a questão da prática, da ação do aluno num processo de aprendizagem, é fator fundamental. Porém, o que vem a ser essa ação, na ótica dos professores investigados?

A análise das categorias iniciais que compõem o conjunto ação do aluno revelaram 
que a noção de praticar articulava em torno de si outras formas de indicação de uma intervenção do aprendiz, formas estas mais genéricas como participação, vivência, captação de idéias. Fazer, trazer para a ação os conhecimentos conceituais, pareceu ser uma das noções básicas desses professores quando questionados sobre sua concepção de aprender.

Tabela 5. Argumentos que definem modelo implícito de aprendizagem dos docentes relativo à educação em geral

\begin{tabular}{|c|c|c|c|c|c|}
\hline Categoria inicial & $\mathbf{F}$ & $\%$ & $\begin{array}{c}\text { Categoria } \\
\text { global }\end{array}$ & $\mathbf{F}$ & $\%$ \\
\hline prática & 3 & 25 & \multirow{5}{*}{$\begin{array}{l}\text { Ação do } \\
\text { aluno }\end{array}$} & \multirow{5}{*}{6} & \multirow{5}{*}{50} \\
\hline vivência & 1 & 8 & & & \\
\hline capta uma idéia & 1 & 8 & & & \\
\hline participação & 1 & 8 & & & \\
\hline tem interesse & 2 & 17 & & & \\
\hline depositado interesse & 1 & 8 & \multirow{2}{*}{$\begin{array}{l}\text { Pré-requisitos } \\
\text { aluno }\end{array}$} & \multirow[t]{2}{*}{4} & \multirow[t]{2}{*}{33} \\
\hline motivação & 1 & 8 & & & \\
\hline info. adequadas & 8 & & $\begin{array}{c}\text { Ènfase no } \\
\text { ensino }\end{array}$ & 2 & 16 \\
\hline recursos & 1 & 8 & & & \\
\hline Total argumentos & 12 & 100 & & 12 & 100 \\
\hline
\end{tabular}

A categoria global pré-requisitos do aluno acabou complementando essa idéia inicial, pois mostrava que a ação do aluno estaria diretamente ligada a motivações internas, interesse, aspectos esses que viriam do próprio aluno ou que lhe seriam despertados. A rigor, somando-se os dois conjuntos de argumentos, $83 \%$ dos dados recolhidos revelaram que o professor de informática de escolas desse campo da cidade de Campinas, atribuiria ao aluno, quase que exclusivamente, a responsabilidade do aprendizado.

Deve-se levar em conta que esses docentes atuavam junto a alunos que buscariam uma formação técnica (na maioria dos casos das escolas investigadas), constituindo-se um eixo de capacitaçâo que poderia ser visto como estando um tanto paralelo à estrutura de ensino formal.

Todavia, isso parece-nos insuficiente para que professores atribuam somente $16 \%$ do total de argumentos recolhidos à variáveis como o contexto de aprendizagem, incluindo-se aqui referências e análises aos métodos de ensino e aos recursos utilizados. Note-se que a figura do professor foi praticamente inexistente no discurso dos docentes, exceto num argumento que sequer deixa claro se é da ação do professor que se fala: "depositado o interesse no aluno". Quem o faria? Quem estimularia o aluno a interessar-se pelo tema que escolheu? O professor? Colegas? Outras pessoas do convívio do aluno? A própria relação com a disciplina em questão? E o grau de conhecimento do professor, a segurança que passa quanto ao fato de ser detentor de um saber que poderá ser dividido? E a organização do currículo, dos programas de curso? Nem mesmo essas referências, freqüentemente usadas em análises e avaliações de formações, não apareceram no discurso dos professores.

Já quando explorado seu modelo implícito de aprendizagem especifico para a formação à informática, a distribuição dos argumentos recebeu um tratamento diferente por parte dos professores.

Três categorias foram igualmente identificadas nos argumentos dos sujeitos, categorias essas que correspondem às orientações anteriores, utilizadas para a análise da aprendizagem em geral. Todavia, o peso de cada categoria achou-se modificado nessa nova ótica.

Assim: a ênfase na ação do aluno perdeu importância (37\% dos argumentos recolhidos, contra $50 \%$ na questão anterior), em favor da categoria global ênfase no ensino (32\% dos argumentos recolhidos). A terceira categoria presente, os pré-requisitos do aluno, pareceu 
manter sua importância, aparecendo com 32\% dos argumentos recolhidos (contra 33\% na questão anterior).

Tabela 6. Argumentos que definem modelo implícito de aprendizagem dos docentes relativo

à formação à informática

\begin{tabular}{|c|c|c|c|c|c|}
\hline Categoria inicial & $\mathbf{F}$ & $\%$ & $\begin{array}{c}\text { Categoria } \\
\text { global }\end{array}$ & $\mathbf{F}$ & $\%$ \\
\hline participação & 1 & 5 & \multirow{7}{*}{$\begin{array}{c}\text { Ação do } \\
\text { aluno }\end{array}$} & \multirow{7}{*}{7} & \multirow{7}{*}{37} \\
\hline vivência & 1 & 5 & & & \\
\hline passa tempo com micro & 1 & 5 & & & \\
\hline capta uma idéia & 1 & 5 & & & \\
\hline aplicação & 3 & 16 & & & \\
\hline tem interesse & 2 & 11 & & & \\
\hline depositado interesse & 1 & 5 & & & \\
\hline & 1 & 5 & \multirow{4}{*}{$\begin{array}{l}\text { Pré-requisitos } \\
\text { aluno }\end{array}$} & \multirow[t]{4}{*}{6} & \multirow[t]{4}{*}{32} \\
\hline gostar de exatas & 1 & 5 & & & \\
\hline raciocínio lógico & 1 & 5 & & & \\
\hline recursos & 3 & 16 & & & \\
\hline conceitos pedagógicos & 1 & 5 & \multirow{3}{*}{$\begin{array}{c}\text { Ênfase no } \\
\text { ensino }\end{array}$} & \multirow[t]{3}{*}{6} & \multirow[t]{3}{*}{32} \\
\hline planeja/o curso adequado & 1 & 5 & & & \\
\hline aulas + prática & 1 & 5 & & & \\
\hline Total argumentos & 19 & 100 & & 19 & 100 \\
\hline
\end{tabular}

Observando-se mais atentamente os argumentos da categoria mais representada, a ação do aluno, constatou-se que os conteúdos apresentados não diferiam, em geral, daqueles apresentados na questão sobre a aprendizagem de outras disciplinas. Somente uma formulação deixava evidente o fato de tratar-se de formação à informática, quando o docente afirmava que o aluno aprende quando "passa grande parte do tempo com o micro". Infere-se dessa colocação a idéia de "interação", de prática, mas pouco sobre o que essa relação pode efetivamente trazer para o aluno.

Desse modo, embora o contingente geral de respostas some uma ênfase ainda grande na responsabilidade do aluno pelo processo de aprendizagem, constatou-se que a ênfase no aluno passou de $83 \%$ dos argumentos (questão anterior), para $69 \%$ dos argumentos, quando solicitava-se o posicionamento na formação à informática. Essa queda de importância gerou um acréscimo de atenção do professor na dimensão do ensino propriamente dito, com referência aos métodos e à estrutura de curso.

Quanto ao conjunto pré-requisitos do aluno, notou-se pelas respostas que além dos argumentos já apresentados na questão mais geral, tais como interesse, motivação etc, a novidade esteve na ênfase dada à informática como tecnologia, que apareceu com os argumentos "ter que gostar de exatas" ou "ter raciocínio lógico”.

A rigor, essas colocações também seriam apropriadas para alunos que estivessem estudando eletrônica, projetos industriais, etc. Isto porque, a generalidade das funções subjacentes às condições "gostar de exatas" e "ter raciocínio lógico", permitiria a transferência para outras atividades técnicas, revelando que pouco de específico tinha o discurso do professor quanto ao processo de aprendizagem da informática em si.

$\mathrm{Na}$ verdade, aspectos como habilidades com conceitos abstratos (como o conceito de inormação, de memória, por exemplo), habilidades matemáticas e espaciais (onde se estocam as informações? como?), possibilidade de extrair relações de dados concretos e situações (uma das condições necessárias para o desenvolvimento adequado de um programa, feito por um programador, por exemplo), capacidade de análise e de síntese, etc, não foram citados pelos sujeitos investigados. Do mesmo modo, toda a dimensão da relação social do trabalhador com a informática foi esquecida pelos docentes, aspecto fundamental para o exercício profissional de um técnico em programação. 
Como gerar um programa que possa ser compreendido e usado eficazmente por seu utilizador, levando-se em conta as dificuldades das pessoas em lidarem com a tecnologia? Como perceber as características e dificuldades de um utilizador de micro, de maneira que o técnico em processamento de dados possa resolver os problemas de interação entre utilizador e máquina que, inevitavelmente surgirão?

\section{Conclusões}

Uma primeira conclusão refere-se à necessidade premente de se efetuar pesquisas específicas sobre a formação à informática. É lugar de dizer-se aqui da grande quantidade de trabalhos nesse campo feitos no exterior, acerca por exemplo, das mais adequadas maneiras de se formar à informática. A necessidade desse tipo de atividade científica se mostra, no exterior, a partir das dificuldades e mesmo ineficiência de treinamentos, quando de sua utilização em contexto prático pelo indivíduo. Esses casos são mais freqüentes em formações voltadas para profissionais ligados à empresas, que esperam, em curto espaço de tempo tornarem-se habilitados a usar essa nova ferramenta em seu trabalho.

Esse mesmo quadro se manifesta no Brasil, embora as pesquisas no campo pareçam ainda muito reduzidas, principalmente se pensarmos numa abordagem em Psicologia Cognitiva. No caso específico da formação na cidade de Campinas, ficou ainda mais complicado, pois temos consciência de que só a continuidade dos trabalhos poderiam dar uma idéia mais clara, por exemplo, do âmbito de cobertura dos cursos na cidade.

Nesse sentido, pudemos constatar que 20 instituições formavam à informática na cidade. Porém, não conseguimos ter a certeza de que este é verdadeiramente o parque existente na cidade. Preferimos nos colocar nessa posição, pois parece-nos leviano tirar as conclusões cabíveis a esse conjunto de dados, se pensarmos no contingente demográfico da cidade è no que ela representa em termos de polo de desenvolvimento no país. Isso porque, conclusão mais óbvia seria dizer que a cidade estaria longe de trabalhar no sentido e formar profissionais na área, de modo a responder às exigências do mercado, partindo-se do princípio que a informática estaria gradualmente constituindo-se em condição para a sobrevivência de profissionais no mercado de trabalho.

Todavia, a continuidade desse raciocínio exigirá, num primeiro momento, que se caracterize um pouco melhor a necessidade de profissionais em informática na região, em termos de número de ofertas de emprego e de suas exigências, relacionadas com a composição dos currículos de escolas voltadas para essa formação.

Pudemos constatar em nossa amostra, que existem na região escolas que oferecem diplomas diferentes de processamento de dados, e que incluem a disciplina informática como elemento de uma formação mais ampla. Do mesmo modo e no outro extremo, constatamos a presença de escolas cujo objetivo único pareceria ser o de fornecer formações a curto prazo (três dias, por exemplo), o que resolveria talvez um problema pontual, mas estaria longe de capacitar um profissional para o uso da informática em seu trabalho.

A pergunta fica: existe uma orientação, uma política (informal que seja) de formação à informática na região? Esse aclamado pólo de desenvolvimento, não teria por exigência conhecimentos de informática? O que é ensinado nas escolas, sejam elas especializadas em informática ou não, é fruto de uma análise do mercado, feita pelos donos das escolas, ou reflete uma visão técnica "do que é necessário se saber para 
atingir níveis diferentes de profundidade no assunto"?

Nossa atividade exploratória não previa essa realidade, já que nosso referencial (embora o soubéssemos extremado) era o mesmo trabalho feito em uma cidade francesa de tamanho equivalente à Campinas, que contava, em 1989/90 com 100 estabelecimentos de informática.

No tocante ao uso de vídeo na formação à informática, tem-se aqui um outro aspecto importantíssimo: identificou-se certa prédisposiçâo de coordenadores pedagógicos e instrutores, quanto ao uso desse recurso na formação. Todavia, sabemos de antemão que os produtos existentes no mercado são obsoletos e pouco variados em relação ao grau de evolução da informática. Essa pré-disposiçâo suporia então, a elaboração de produtos? E uma vez elaborados, como usariam esse material, como articulariam a prática com a máquina, exposições teóricas e mensagem audiovisual?

Como não era nossa preocupação nesse momento explorar métodos de uso de vídeo na formação à informática, pois sequer sabíamos da possibilidade do professor acreditar na pertinência desse suporte nessa formação, seria necessário um aprofundamento que respondesse tantas das questões geradas pelo estudo inicial. Essas colocações são importantes pois, como demais instrutores e profissionais da área, a crença de que é só usando o microcomputador que o aluno aprenderá o que vem a ser informática esteve presente no grupo investigado. Além disso, as argumentações que sustentam a prédisposiçâo dos professores baseiam-se em conceitos extraídos de pesquisas voltadas para imagem fixa.

Um último ponto a ser ressaltado refere-se ao aprofundamento de pesquisas sobre métodos de ensino especificamente, dentro dos quais a articulação vídeo, micro, e outros suportes possa ser investigada, mas vista sob o prisma dos professores. Isso é dito porque, se lembrarmos que o modelo implícito de aprendizagem dos coordenadores e instrutores investigados, principalmente no que tange à formação à infor- mática, concentrava-se no aluno (quase 70\% dos argumentos identificados referem-se a esse sujeito), que os demais $30 \%$ são voltados para métodos de ensino, e que a figura do instrutor, da relação que estabelece com o aluno, sequer aparece, fica fundamentada nossa preocupação.

\section{Referências Bibliográficas}

Bardin, L. (1996) L'analyse de Contenu. PUF. Paris.

Bélisle, C., Rosado, E. M. S. (1990). Bureautique et formation, in Informatique et différences individuelles. Presses Universitaires de Lyon. Lyon.

Hoc, J. M. (1978) Psychologie Cognitive de la planification. PUG. Grenoble.

Jodelet, D. (1995). Représentation sociale: phénomènes, concept et théorie, in Psychologie Sociale, org. Moscovici, PUF. Paris.

Malglaive, G. (org) (1987). Quelle pédagogie pour les nouvelles technologies? Recherche en formation continue. Ministère des Affaires Sociales et de l'Emploi Délégation de la formation professionelle. Documentation Française. Paris

Moscovici, S. (1978) A representação social da Psicanálise. Zahar Editores. Rio de Janeiro.

Rosado, E. M. S. (1990) Communication médiatisée et processus d'évolution des représentations. Étude de cas: la représentation de l'informatique. Tese de Doutoramento. Université Lumière Lyon II. Lyon.

(1992). comunicação mediatizada e processo de evolução de representações. estudo de caso: a representação da informática. in anais do i conpe - abrape. Editora Átomo, Campinas.

(1994a) O alcance do vídeo na sala de aulas, in $\mathrm{O}$ vídeo no campo da educação. Editora Unijuí, Ijuí.

(1994b). Vídeo e aquisição de conhecimentos: alguns elementos de uma metodologia de pesquisa. In, INTERCOM, vol XVII. $\mathrm{N}^{\circ} 2$, julho/dezembro. 